\title{
A best practice in education and support services for independent living of intellectually disabled youth and adults in Mexico
}

\author{
Gregorio Katz, MD, (I) Guillermina Rangel-Eudave, BS in Psic,,(I) \\ Betania Allen-Leigh, PhD, (2) Eduardo Lazcano-Ponce, MD, ScD. (2)
}

Katz G, Rangel-Eudave G, Allen-Leigh B, Lazcano-Ponce E. $A$ best practice in education and support services for independent living of intellectually disabled youth and adults in Mexico. Salud Publica Mex 2008;50 suppl 2:SI 94-S204.

\begin{abstract}
This article describes a best practice in the field of intellectual disability, a program for independent living offered by the Center for Integral Training and Development (CADI per its abbreviation in Spanish) for people with intellectual disability in Mexico. A detailed description of an effective program that fosters autonomy, social inclusion and high quality of life in people with intellectual disability is presented. The program encompasses four areas: a) a therapeutic academic area that teaches applied living skills; b) development of social skills; c) development of vocational skills, and d) skills for independent living.The program is divided into three levels: a) initiation to independent living, where clients develop basic abilities for autonomy, b) community integration and social independence, which provides clients with the skills necessary for social inclusion and economic independence, and c) practical and psychological support, which offers counseling for resolving psychological issues and enables subjects to maintain their autonomy.
\end{abstract}

Key words: intellectual disability; independent living; best practice; Mexico
Katz G, Rangel-Eudave G, Allen-Leigh B, Lazcano-Ponce E. La mejor práctica en servicios educativos y de apoyo para la vida independiente para jóvenes y adultos con discapacidad intelectual en México. Salud Publica Mex 2008;50 supl 2:S194-S204.

\section{Resumen}

Este artículo describe una "mejor práctica" en la capacitación para el logro de vida independiente, inclusión social y alta calidad de vida en personas con discapacidad intelectual. Se describe en detalle del programa ofrecido por el Centro de Capacitación y Desarrollo Integral (CADI), en México. Dicho programa tiene cuatro áreas: I) área académicoterapéutica para el desarrollo de destrezas prácticas para la vida independiente; 2 ) área para el desarrollo personal y de habilidades sociales; 3 ) área para el desarrollo de habilidades laborales; y 4) área para el desarrollo de habilidades aplicadas a la vida independiente. El programa se divide en tres niveles: a) iniciación a la vida independiente, donde se desarrollan las habilidades básicas necesarias para el logro de su autonomía; b) integración comunitaria e independencia social que provee a los clientes las destrezas necesarias para su inclusión social e independencia económica; c) apoyo práctico y psicológico que ofrece asesoría para resolver problemas psicológicos y el logro de su autonomía.

Palabras clave: discapacidad intelectual; vida independiente; mejor práctica; México

(I) Capacitación y Desarrollo Integral AC, Estado de México, México.

(2) Centro de Investigaciones en Salud Poblacional, Instituto Nacional de Salud Pública, Cuernavaca, México.

Accepted on: September 20, 2007

Address reprint requests to: Dr. Eduardo Lazcano-Ponce. Centro de Investigaciones en Salud Poblacional, Instituto Nacional de Salud Pública. Av. Universidad 655, Col. Santa María Ahuacatitlán, 62508, Cuernavaca, Morelos, México

E-mail:elazcano@insp.mx 
$\mathrm{T}_{\mathrm{H}}^{\mathrm{s}}$ his article provides a description of a best practice in the field of intellectual disability. This best practice consists of an education and support program oriented towards facilitating independent living by adolescents and adults with mild to moderate intellectual disability in a middle-income country, where services and public policy related to this issue are sorely lacking. The text examines the specific methods through which optimal outcomes (high quality services for people with intellectual disability) are achieved in the specific context of Mexico. The best practice described is an educational process and support system that teaches the necessary skills and then provides continued practical support for independent living accompanied by social inclusion. ${ }^{1,2}$ This service constitutes a best practice in that greater client satisfaction (that of people with intellectual disability and their families as legal guardians) and higher quality of life have been achieved with greater cost-effectiveness. ${ }^{3}$

Best practices are initiatives that make outstanding contributions to improving the quality of service or in general, the quality of life. The term is often used to refer to health promotion, health care and services focusing on social wellbeing but can also be applied to business practices and other services. ${ }^{4-7}$ Reports of a best practice provide an overview of a method, program or intervention that is more effective at delivering a particular outcome than other methods or programs. ${ }^{8} 9$ This article provides a description of a program that is more effective at delivering autonomy, social inclusion and in general high quality of life to people with intellectual disability in a middle-income country. ${ }^{10}$ The concept of best practice provides a framework in which to situate this specific approach to the education and support of adolescents and adults with intellectual disability in Mexico. ${ }^{11}$

Although scientific publications address the need for services, types of services offered and quality of the services and interventions in the field of intellectual disability, they almost invariably focus on high-income countries. ${ }^{12-14}$ There is limited information, and almost no scientific publications, about the existence, the need for and the quality of services for people with intellectual disability residing in middle- or low-income countries. ${ }^{15,16}$ Therefore this article presents an overview of a best practice, which constitutes a model for both education and continued support for autonomy and social inclusion with quality of life, in a middle-income country, Mexico.

\section{Background}

Training centers for developing skills needed for independent living and autonomy in people with mild to moderate intellectual disability have been established successfully in developed or high-income countries for 50 years, beginning with legislation passed in the state of California, USA, in 1954, which required integration of people with intellectual disability into society through community residence and employment. ${ }^{17,18}$ Education for independent living by people with intellectual disability has proven more cost-effective than traditional programs which institutionalize this population. ${ }^{19}$ In high-income countries, an estimated $25 \%$ of people with intellectual disability live with their families and 50\% live independently in community residences. ${ }^{20}$ However, in middle- or low-income countries, governmental programs promoting independent living among people with intellectual disability are virtually nonexistent and private services that provide training for autonomy in this population are rare.

Families with a member with intellectual disability in middle- or low-income countries have to cover catastrophic expenses for mental or physical health care and have to support that family member for his or her entire life, since the State does not offer an organized social response for people with intellectual disability after childhood. Research indicates that public policy and services should focus on community integration and economic independence of people with intellectual disability, since this is more cost-effective for both the State and individual families and also offers greater quality of life for people with this type of disability. ${ }^{21,22}$

The absence of health or public policies which stem from current scientific knowledge about intellectual disability, which does occur in Mexico, generates incompetence for social integration and prevents people with intellectual disability from having an independent life project. This leads to a higher incidence of physiological and mental health problems, including more depression, irritability, anger, and in general antisocial or challenging behavior, in adolescents and adults with intellectual disability. ${ }^{23,24}$

Self-determination to live and work within a community is the principal indicator of quality of life for people with intellectual disability. ${ }^{25}$ Consequently, parents and families of people with intellectual disability have as their highest expectation, explicitly or implicitly, employment and integration of their family member into the community. ${ }^{26}$ Programs that include communitybased residence are an efficient alternative for reaching these goals; it has been widely documented that people with intellectual disability who live independently in community settings increase their skills and adaptive behavior. ${ }^{27}$

In addition to the scarcity of human resources, public policy to serve the intellectually disabled in 
middle- and low-income countries, there is a lack of a knowledge-base for early diagnosis and correct management for this problem. This is due to the absence of training and accreditation programs for health and education specialists. ${ }^{28}$ In addition, given the greater frequency of health needs in this vulnerable population, good accessibility to primary health care and to complementary secondary and tertiary medical attention is needed. ${ }^{29-32}$ In Mexico, for example, access to medical insurance (private or social security health care) is not available for people with intellectual disability.

The principal outcomes of a successful program for community integration of people with intellectual disability are: reduction of behavioral problems; social abilities for community life; regular recreational activities and good distribution of free time; fostering of family and other social contacts; practical skills needed to run a household; self-determination; acceptance and assimilation into the community; and involvement in paid employment. ${ }^{33}$ An essential aspect of community integration is the type of residence (larger or smaller groups, individual residence or living with the family of origin), since studies in high-income countries have shown that individuals with intellectual disability who live in small residence groups have greater social networks, increased possibilities for self-determination and a lower risk of exploitation. ${ }^{34-37}$

Promotion of independent living among individuals with intellectual disability requires identification of their needs, training in a range of practical skills and adequate prospective monitoring. ${ }^{38}$ Therefore, this article presents an example of a program that has provided this type of training and monitoring for over twenty years, inasmuch as it constitutes a model for Latin American and in general middle-income countries and therefore can be considered a best practice in this field.

\section{Best practice: the training at an independent living and support program for people with intellectual disability in Mexico}

The best practice herein reviewed is the group of services offered by the Center for Integral Training and Development (CADI, per its initials in Spanish. http:/ / www. cadi.org.mx/), a non-profit, non-governmental organization which provides training and support for independent living and social inclusion of adolescents and adults with intellectual disability, in central Mexico.

Given that it is not possible to cure or eliminate mental retardation, all individuals should be provided with the necessary means for normalizing their behavior in order to prevent negative differentiation from the rest of society. A number of different types of programs for training and integral development for independent living by individuals with intellectual disability exist in high-income countries. ${ }^{39-41}$ In middle- and low-income countries, particularly in Latin America, programs which facilitate independent living and allow self-determination and autonomy by people with intellectual disability are virtually nonexistent. However, in 1984 the CADI was established in central Mexico; it is a unique institution of its kind in Latin America. Over two decades in operation, this program has successfully trained over 200 adolescent and adult clients.

The objective of any independent living program for people with intellectual disability is social inclusion of those individuals who have subnormal intelligence, enabling them to function at their maximum potential by eliminating behaviors that interfere with social integration. This is achieved through the acquisition of four basic goals: a) practical or applied academic capabilities; b) community integration; c) paid employment, and d) independent life or considerable autonomy.

The program offered by CADI to adolescents and adults with intellectual disability covers four areas. Given that in Mexico an overwhelming proportion of children with intellectual disability do not attend school, most clients arriving at CADI require academic instruction utilizing techniques designed for the learning disabled, aimed at providing them with applied reading, writing and arithmetic abilities. This therapeutic academic training constitutes the first of the four areas. These individuals do not have social skills due to overprotection or rejection by their families, which has isolated them from social interaction. Therefore, another area focuses on imparting social skills and teaching appropriate management of free time, in order to facilitate social integration. Given the lack of previous schooling, clients also require vocational training in order to develop work-related abilities (devoting a proportion of their time to work and linking achievement of production goals to rewards) and the necessary technical skills for subsequent employment. Once the goals of the three previous areas have been achieved, clients are then integrated into residential groups (six persons to an apartment) for applied training in management of domestic affairs necessary for independent life. Once clients have completed the program, CADI provides continued psychological and practical support (for money management, difficulties at work and household management issues) through weekly advising sessions, which gradually taper off. 


\section{Entry into CADI's independent living program}

Adolescents or young adults with intellectual disability who join CADI's independent living program are evaluated at the outset in terms of neuropsychological, academic level and abilities required for the four program areas mentioned above. The evaluation establishes the level at which each person will begin an individualized training program. Likewise, the client's family is evaluated to establish emotional and psychological needs; this evaluation initiates the counseling process for parents and family members.

Admission to the program is determined through the initial evaluation, to select clients who will benefit from the program. This is the group of people known as self-sufficient or high-functioning, which includes individuals with moderate to mild intellectual disability, borderline or low-average intelligence with severe learning disabilities (which lead to a functional level similar to people with borderline intelligence). For this group, the goal of CADI is independent living and social inclusion. Another small group is made up of clients with severe mental retardation (low-functioning); for this group, CADI aims to develop self-care abilities that allow a certain level of basic autonomy, yet within the context of caretaking, dependency and custody by adult guardians. Individuals with schizophrenia are excluded from the program.

In most middle- and low-income countries, individuals with borderline or low normal intelligence with learning disability are very vulnerable, and therefore can benefit greatly from a program of this nature. Having had their academic opportunities cut short, often before finishing elementary or junior high school, they require an individualized program like the one CADI offers, and which provides training to compensate for the lack of educational opportunities. The vulnerability of these subjects stems from frustration with their educational failure and loss of self-esteem due to rejection or criticism by parents, teachers and peers. In individuals with learning disabilities this situation produces rebelliousness, defiance or passivity towards joining the workforce.

The duration of the program for each client depends on a number of factors, including age at entry into the program, level of neurological integration and social adaptation, and the emotional situation of the client and his or her family. The average stay in the training and integral development program is five to eight years.

\section{Processes in the education and support program}

The independent living program offered by CADI to people with intellectual disabilities is divided into three levels (table I). Level I, Initiation to independent living, includes children between 5 and 13 years of age. In this level, clients develop the basic skills for autonomy and independence, to counteract family overprotection, and taking into account their individual limitations. After completing Level I, adolescents and adults go on to Level II, Community integration and social independence, where they acquire the skills necessary for social inclusion and economic independence. Level III, Continued psychological and practical support, includes support for maintaining autonomy and counseling to resolve any psychological, emotional or social problems for each individual.

Level I, Initiation to independent living, is in turn divided into two stages. Clients enter a specific level depending on previously acquired skills, measured during the initial evaluation. Level I includes three dimensions: sensory motor skills, social adaptation and cognitive abilities. An individualized educational plan is designed, taking into account the client's abilities upon entry to the program.

\section{Level I-Basic skills for independent living}

The central objective of Level I is the development of basic skills for achievement of each client's maximum potential. In the sensory motor dimension, therapy is geared towards posture and balance, providing adequate organization and quality of movement. The aim is to inhibit or eliminate pathological movement patterns and substitute them with normal ones. The program targets regularization of postural tone and sensory integration to rehabilitate the client with problems in muscular tone. Given that optimal speech and breathing depend on the muscular tone of the face, neck and chest, therapy focuses on regularizing the tone of these areas, while diminishing hypersensitivity. This process prepares each individual for adequate verbal articulation and lessens the risk of upper respiratory tract infections. One of the most frequent sequelae of postural tone deficiencies relates to ocular musculature, altered ocular accommodation and fixation, which affects either central or peripheral vision or at times both. To manage this problem, ocular motor function 
Table I

\section{Objectives of the three levels of the independent living training program at the Center for Integral Training and DeVelopment, MeXico}

Area of development

Level I. Development of basic functions

Sensory motor
Inhibition of pathological patterns and acquirement of normal patterns of equilibrium and movement.

- Regularization of muscular tone of the face, throat and thorax.

- Diminished hyper-sensitivity.

- Preparation for adequate language articulation.

- Adequate ocular alignment and tracking.

- Adequate precision in postural adjustments for equilibrium.

\begin{tabular}{lll}
\hline Social adaptation & $\begin{array}{l}\text { Promotion of acceptance of the child's diagnosis by } \\
\text { parents and elimination of rejection and negation, and } \\
\text { culmination of the grief process. }\end{array}$ & $\begin{array}{l}\text { Introduction of parents and their children to the } \\
\text { humanistic behavioral method. }\end{array}$ \\
\hline Cognitive & $\begin{array}{l}\text { Promotion of language and symbolic perceptual } \\
\text { organization. }\end{array}$ & $\begin{array}{l}\text { Preparation for development of symbolization. } \\
\text { Stimulation of mental representation to promote } \\
\text { language construction. }\end{array}$ \\
Establishment of guidelines for integrating rules for \\
social interaction.
\end{tabular}

Level II. Social independence and community integration

\begin{tabular}{|c|c|c|}
\hline Sensory motor & $\begin{array}{l}\text { Adequate development of postural control and motor } \\
\text { coordination. }\end{array}$ & $\begin{array}{l}\text { - Adequate posture. } \\
\text { - Correct gross motor coordination. } \\
\text { - Ability to participate in sports. } \\
\text { - Ability to interact with the physical environment. }\end{array}$ \\
\hline Social adaptation & Continued promotion of family and social integration. & $\begin{array}{l}\text { - Formation of a sense of belonging to a group or social } \\
\text { normalization } \\
\text { - Family and social acceptance } \\
\text { - Integration of independent living groups }\end{array}$ \\
\hline Cognitive & $\begin{array}{l}\text { Advanced skill acquirement: } \\
\text { - Advanced language structure; } \\
\text { - Initiation to writing; } \\
\text { - Mechanical reading } \\
\text { - Logical reading process; } \\
\text { - Logical writing; } \\
\text { - Mathematics; } \\
\text { - Practical living skills. }\end{array}$ & $\begin{array}{l}\text { Development of linguistic structure: correct use of } \\
\text { past, future, adverbs, etc., until structured thought is } \\
\text { achieved. } \\
\text { - Visual-auditory-motor integration in mental } \\
\text { representation of writing. } \\
\text { - Recognition of phonemes, perceptual constancy, } \\
\text { foreground-background, spatial position and direction, } \\
\text { prosody. } \\
\text { - Analysis and synthesis of information received. } \\
\text { - Possibility of logical writing using sentences. } \\
\text { - Emphasis on logics and mechanics with } \\
\text { - Somprehension of } 30 \% \text { of basic content. } \\
\text { - Initiation in abilities for employment. }\end{array}$ \\
\hline \multicolumn{3}{|c|}{ Level III. Continued practical and psychological support } \\
\hline Academic-therapeutic & $\begin{array}{l}\text { Application of academic knowledge of mathematics, } \\
\text { reading and writing and in general exploiting the person's } \\
\text { cognitive potential. }\end{array}$ & $\begin{array}{l}\text { - Manage a budget, with income and expenses. } \\
\text { - Use of mass media. }\end{array}$ \\
\hline \multirow[t]{2}{*}{ Personal development } & Developing an adequate level of personal autonomy. & $\begin{array}{l}\text { - Use of public transportation. } \\
\text { - Self-care of health. } \\
\text { - Implementing measures for protection and security. } \\
\text { - Developing basic domestic activities. } \\
\text { - Adequate use of free time. }\end{array}$ \\
\hline & Developing and maintaining interpersonal relations. & $\begin{array}{l}\text { - Developing sexual consciousness and education. } \\
\text { - Developing civic consciousness. } \\
\text { - Developing environmental awareness. }\end{array}$ \\
\hline
\end{tabular}


Continued

Employment skills Ability to seek and maintain paid employment at the minimum wage level.
- Achieve pre-vocational training.

- Achieve vocational training.

- Development of skills and discipline for looking for work.

- Developing appropriate expectations for employment by trained persons with intellectual disability.

- Integration into different types of employment.

- Compliance with time schedules, goals, productivity.

Independent, community residence and domestic management

Ability to manage domestic life in an independent manner.
- Maintenance of a dwelling (apartment).

- Planning and preparing meals.

- General and food shopping.

- Washing, ironing and care of clothing.

- Simple domestic repairs. therapy is used in order to achieve adequate alignment and ocular tracking.

In the social adaptation area the program includes working with both the person with intellectual disability and his or her parents or guardians. It is well known that the emotional wellbeing of people with intellectual disability depends to a great extent on acceptance by parents and their social milieu in general. ${ }^{42-44}$ Taking into consideration the narcissistic wound, ${ }^{45}$ a phenomenon suffered by parents who seek their own transcendence in their children or deposit their future expectations in their children, one can understand why parents have a hard time accepting their child's disability. This psychological issue must be dealt with through proper and early diagnosis of intellectual disability, since the lack of a diagnosis constitutes an obstacle for resolution of parents' psychological trauma which in turn frequently leads to recurrent emotional maltreatment or even physical abuse. When diagnosis takes place and is accepted by parents, there is a better prognosis for early and effective treatment or education of the child. When parents of a child with intellectual disability are given their child's diagnosis, they should receive psychological support in order to eliminate rejection, negation and facilitate the grief process, which allows acceptance of their child and his or her limitations.

Parents' lack of acceptance of their child results in an inability to control their child's behavior, which in turn gives rise to aggressive and challenging behavior and often finally leads parents to seek education and therapeutic services. ${ }^{46-49}$ Therefore, long-term counseling and guidance for parents are needed to identify and deal with behaviors that interfere with healthy family interaction, socialization and opportunities for learning by the intellectually disabled child..$^{50-55}$ Behavioral problems are also observed due the lack of motor or impulse control. On occasion, when the clinical profile of a client includes self-stimulation or auto-aggression that prevents the individual from learning or cooperating in therapy, treatment begins exclusively with humanistic, client-centered behavioral therapy (adapted to this population). ${ }^{*}$

In the cognitive area, work with clients is based on their level of development and employs symbolic psychomotor therapy, pre-writing therapy and language therapy. In terms of psychomotor skills, there are three possible options: constructive, targeted and behavioral psychomotor training. The intervention promoting constructive psychomotor skills covers the sensory-motor stage and provides the person with intellectual disability with a receptive language in an environment specially prepared so that he or she can explore space, body movements and enjoy organized movement. This facilitates the discovery of causality through physical, spatial, temporal and mathematical aspects which will lead the individual towards symbolic thought and initial mental structures - prerequisites for developing the preoperational stage.

Once the sensory-motor stage is completed, the targeted psychomotor intervention follows. At this point the client with intellectual disability is ready to take on the preoperational stage. Targeted psychomotor skills and cognitive training stimulates the reconstruction of

\footnotetext{
* Humanistic behavioral therapy emphasizes people's innate abilities to achieve self-fulfillment and focuses on helping people grow in their self-awareness and self-acceptance. Humanistic therapy encourages people to take responsibility for their actions and feelings and tends to focus on the present instead of the past. (Association for Advancement of Behavior Therapy, What to expect from psychotherapy. Fact sheet. 2001. Available at www.aabt. org / 091101\%20Folder/091101/public/ what_to_expect.html)
} 
the past and eventually attempts to lead the person to look forward to and conceiving the future.

To stimulate mental representation, training includes deferred imitation; the internalization of the actions carried out allows the individual to repeat these same actions at the appropriate time, to facilitate oral language expression. At this point symbolic play is promoted, placing the individual in situations where he or she has to pretend. Building games is also promoted, including management of form, size, color and texture, which leads to appropriate perceptual organization and topological notions, thereby teaching the pre-requisites for reading, writing and arithmetic.

Behavioral psychomotor training establishes the patterns that will permit a client to acquire basic rules for social interaction with concepts such as correct and incorrect, allowed and not allowed, taking turns and respecting another's turn, and paying attention to instructions, among others. This type of training also includes developing an individual's ability to postpone gratification. Symbolic psychomotor training includes exercises to learn to pay attention and concentrate, as well as exercises on how to plan, anticipate and organize one's behavior. Through these strategies, clients are gradually guided towards adapting to their social environment. In addition, pre-writing therapy is provided simultaneously with the last stage of symbolic psychomotor training, and allows clients to acquire basic abilities for legible handwriting at an acceptable speed. ${ }^{56}$

In terms of basic language skills, clients are provided with vocabulary and initial language structure. Since spoken (verbal) language is not achieved by all individuals with intellectual disability, depending on sequelae in the language area, alternative communication methods are taught when necessary, including a communication board, sign language and computers, alone or in combination.

Given that behavior management and generalization of concepts are the two principal elements of rehabilitation for people with intellectual disability, therapy and education includes diverse situations and circumstances encountered in people's lives; this is known as lived experience methodology. Within this approach, therapeutic efforts are carried out both at the institution and within the family environment, given that contact with the community involves a change from structured to open and unstructured environments, which can provoke anxiety and disorganization in people with intellectual disability and have a negative impact on control of motor impulses. This approach takes into account the fact that persons with intellectual disability who behave acceptably (in social terms) in structured situations often develop unpredictable and socially unacceptable behaviors in situations with little structure.

In order for behavioral patterns to be generalized (so behavior is similar independent of the circumstances) lived experience methodology employs real-life community resources such as public transportation, zoos, markets, parks, children's museums, drugstores, malls, supermarkets, and candy stores, among other possible scenarios. At these venues, clients develop impulse control and their capacity to tolerate frustration in the face of situations such as standing in line, waiting, taking turns, communicating their wishes, respecting others, postponing immediate gratification and other issues involved in these situations. In addition, so as to generalize concepts newly acquired through different interventions or educational strategies, these concepts are applied within this lived experience.

\section{Level II-Putting independent living skills into practice}

In Level II of CADI's educational program clients apply the practical skills necessary to live independently. Lived experience methodology implies training to face situations that must be dealt with to meet the persons' individual needs and wishes. Taking as a starting point the developmental levels achieved in Level I, new, farther reaching objectives and goals are defined for Level II, as follows.

In the sensory-motor area, training continues with the advanced level of the Klein Vogelbach's School of Good Walking. ${ }^{57}$ This allows each client to develop adequate posture control, acquiring correct gross motor coordination, preparation for sporting activities, which in turn enables them to interact with the physical environment. Once negative behaviors are eliminated, the program promotes integration by clients into a group of persons who function at the same general level and have similar characteristics (group membership). The psychoaffective area group membership includes processes to accomplish social normalization both within the community and in the family environment. These activities, in addition to promoting the socialization process without the immediate risk of suffering social rejection, provide the possibility of eliminating the egocentricity of people with intellectual disability. ${ }^{58}$ Activities are aimed at clients' learning to enjoy the company of others, share belongings, and choose appropriate recreational activities from what the community has to offer while supervising that behavior complies with social norms and rules.

Finally, at this stage of the program, specific therapies seek to continue the cognitive development of a) advanced language structure; $b$ ) continuation of writing 
skills; c) mechanical reading; d) logical reading process; e) logical writing; f) continuing arithmetic skills; and g) applied areas. Below, we review the basic contents of each type of educational therapy.

Teaching advanced language skills consists of developing deeper linguistic structures such as the correct use of the past and future tenses, adverbs and prepositions, among others, leading to structured thought. Once prewriting skills have been acquired through use of sensory materials, clients are taught skills for use of spatial relations and graphic materials. This training promotes adequate development of fine coordination, which facilitates organized writing movements and creates a specific mental representation of each letter, to progressively include syllables, words, phrases and sentences, which taken together constitute mechanical writing.

In terms of mechanical reading, at this stage the learning process focuses on recognition of phonemes, emphasizing analysis and synthesis of letters when converting them into syllables, words, sentences and paragraphs. Visual, auditory, motor and articulation exercises are carried out, as well as practice of perceptual constancy, foreground-background, spatial position and direction, thus stimulating short- and long-term symbolic memory. This educational model also includes a focus on prosody for acquisition of tone and rhythm. To facilitate the logical reading process, through representations and narrations of illustrated stories (often in the style of comic books) clients with intellectual disability are taught to ask the following key questions: "where?", "when?", "who?", "how?", and "what?" This process is repeated until clients are able to analyze and synthesize the information received. After this has been achieved, stories with illustrations that are broken down into smaller scenes or parts are used to enrich the symbolization process. When clients with intellectual disability can handle a sufficient number of these symbolic representations, they are asked to narrate what they remember from the story. Once this process has been achieved, verbal scenes substitute the illustrations, in order to develop mental representations that allow better language comprehension with ever more sophisticated levels of logical thought and eventually the ability for reading comprehension. At this point, the combination of mechanical writing and reading with logical thought processes allows clients to perform logical writing, to progress from definitions of words to their use in understandable, contiguous sentences. Since most people with mild to middle intellectual disability cannot progress further than the academic equivalent of the fourth year of elementary school, the aim of the educational program is to provide the ability to use reading and writing with intelligence in situations encountered in daily life, since performing these tasks mechanically without comprehension, discernment or reason would limit the usefulness of this logical skill.

At this stage in the educational program, mathematics is also taught and similarly divided into mechanical and logical elements. Logical mathematical thought is developed initially through the acquisition of knowledge of numbers (quantifiers) and the use of concrete, specific materials for the appropriate developmental stage of each client. After this, classification, one-to-one correspondence and series are taught with the practical goal of being able to follow basic orders or directions, and comprehension of $30 \%$ of the fundamental notions in combination with the necessary organizational percepts. This activity requires specific materials that stimulate both manual abilities and group participation in order to achieve pre-established tasks through the use of graphic illustrations that measure individual skills, speed of execution and production goals.

The applied skills area of the program focuses on self-care and personal hygiene. This is also the stage at which precursory employment skills are taught, which build on the abilities the client has achieved in Level I of the program, especially walking or moving with the use of auxiliary devices, elimination of self-destructive and aggressive behaviors, and the possibility of reconstructing the past and projecting onto the future. In Level II of the program, clients develop the basic social structures, which will allow them to deal autonomously with situations that arise when meeting individual needs. In part this is achieved through fostering group membership. Learning to use applied skills in realistic social situations, such as handling money and waiting for, receiving and counting change, is reinforced by reconstructing the experience through the use of role-playing techniques. ${ }^{59}$ Thus, once numbers have been introduced as a concept and coordination and visual-spatial perception have been developed, basic arithmetic operations are learned in progressive order, and always linked to applied, real-life problems to be solved using this arithmetic knowledge. This area culminates with knowledge and identification of bills and coins of different denominations, using sensory teaching materials until clients are able to handle and use money rationally. This function, given its complexity, is continually taught during the entire educational program for independent living.

Under normal conditions, Level II coincides with the end of early or middle adolescence (although individual clients who enter the education program at an older age will of course reach this stage later). The community living program usually starts in late adolescence and includes a series of disciplines necessary 
for autonomy. At this point, the client with intellectual disability has an adequate level of social adaptation, has exploited to the maximum his or her cognitive potential and is ready to begin the individualized program for living independently. Upon completion of Level II of CADI's program, individuals who would have had to depend on others in economic, applied and social matters will be ready to face and adequately deal with everyday situations by themselves and exercise a certain degree of autonomy.

Level II of CADI's educational program is completed when the client (in late adolescence, or in some cases, as an adult) has acquired academic knowledge at the level of a third grade elementary education. In terms of motor skills, the individual is able to achieve adequate posture control and acceptable gross motor coordination, which allow him or her to participate in sporting activities and in general interact with the physical environment. As for applied living skills, clients will have completed a pre-vocational program and then vocational training. In addition, clients will have developed the basic social skills that will allow them to face and solve elemental problems of everyday social interaction in a relatively autonomous manner.

\section{Level III-Continued support services for independent living}

The CADI program is designed to ensure that all individuals who enter the independent living program achieve social, familial and economic self-sufficiency. Therefore, after completing Levels I and II of the program, clients will have acquired the necessary skills for consistent, correct functioning in employment, which will provide them with at least a minimum wage salary. The objective is to integrate groups of six individuals with intellectual disability who live together in an independent group; they depend on each other in practical terms and each member of the residential group contributes his or her minimum wage salary to maintenance of the household, providing the equivalent of six minimum wage salaries for economic support of this (family-type) group. With six minimum wage salaries, in Mexico, the group is able to rent an apartment in the community, purchase food and other items necessary for maintaining a home and have a small amount of funds for leisure activities.

The success of this model depends not only on completion of the educational program but also on continued counseling and support of the individuals who have formed these autonomous residential groups, in order to guide them in solving problems that may arise, thereby maintaining the level of abilities achieved immediately after the person completes CADI's program. The basic premise of these groups of six people is that they share responsibilities (and their social and personal lives) as if they were a family. Through a combination of previous training, support services and collaboration with employers in the community, a large number of people with intellectual disability are able to acquire the skills necessary for leading an independent life in practical, social and economic terms, which allow them to exercise their autonomy. This strategy also offers a solution to the problem of the intellectually disabled person's family having to support him or her economically, when this population is entirely capable, with the right training, to be economically active.

\section{Conclusions}

CADI's successful program has shown that in Mexico, people with intellectual disability can achieve active inclusion into the community, when they are incorporated into the work force and receive necessary training to live autonomously within groups. In order to secure autonomy regardless of the socioeconomic situation of the family of origin, the following four components must be achieved: holding paid employment (with at least a minimum wage salary), forming part of a group membership structure (which makes independent living economically feasible), developing adequate socialization skills, and accomplishing the applied abilities for social inclusion.

In middle-income countries such as Mexico, people with intellectual disability often receive education and diverse types of support services during childhood and up to puberty or adolescence, but after this there are limited options (especially for accessing public, low-cost services). Therefore, the need for a viable alternative -which facilitates practical, social and economic independence of these subjects-, can be met with programs such as CADI's educational model. Unfortunately, in the Mexican context there are a limited number of professionals trained in education for independent living for individuals with intellectual disability. In contrast, in high-income countries, graduate and certification programs exist for training health and educational professionals in supporting community integration and autonomy in people with intellectual disabilities.

It is possible for individuals with intellectual disability to participate in employment, community and family activities, and to be fully integrated into society. However, a high susceptibility of this population to behavioral disorders makes them vulnerable to lost opportunities. ${ }^{60}$ Therefore, applied guidelines for diagnosis and clinical management of intellectual disability, high quality graduate and continuing education for personnel in the mental health and disability fields, 
implementation of clinical, epidemiological and social research on individuals with intellectual disability and interventions to promote quality of life are indispensable in high-, middle- and low-income countries. This is an important public health issue, as people with intellectual disability constitute a large proportion of society. In addition, this population is one of the most vulnerable groups, given its pattern of greater physical morbidity and psychiatric co-morbidity than the general population; it also has many unsatisfied health care and social service needs and is more subject to discrimination and maltreatment. ${ }^{33,61-63}$

CADI constitutes a model for services for people with intellectual disability living in middle-income countries, especially Latin American nations, and also for training of mental and educational professionals in this field. This model is based on scientific research on intellectual disability developed in high-income countries, but adapted to the cultural, social, political and economic idiosyncrasies of the Mexican context; similarly, the model could also be adapted to other middleor low-income country contexts. This recapitulation of the specific strategies involved in this model prompts reflection on and a critique of the limited resources that the health, education and public services in general offer to people with intellectual disabilities in most developing countries, and specifically in Mexico. An organized social response to the needs of people with intellectual disability should concentrate on providing them with the support they need to remove the obstacles that prevent their becoming active, integrated members of society.

\section{Acknowledgements}

This article was developed thanks to funding from the Pegasso group.

\section{References}

I. Lachapelle Y,Wehmeyer ML, Haelewyck M-C, et al. The relationship between quality of life and self-determination: an international study. J Intellect Disabil Res 2005;49:740-744.

2. Bertelli M, Brown I. Quality of life for people with intellectual disabilities. Curr Opin Psychiatry 2006; 19:508-5 I3.

3. Glossary of the European Observatory on Health Systems and Policies, http://www.euro.who.int/observatory/Glossary/TopPage!term=I.

4. Joint United Nations Programme on HIV/AIDS (UNAIDS), http://www. unaids.org/en/.

5. The Joanna Briggs Institute, Research and Development Unit, Royal Adelaide Hospital, and University of Adelaide. http://www.joannabriggs. edu.au/about/home.php.

6. Best Practices Data Base in Improving the Living Environment, http:// www.bestpractices.org/.
7. Best management practice for project, programme, risk and service management, http://www.best-management-practice.com/officialsite.asp. 8. Knobbe CA, Carey SP, Rhodes L, Horner RH. Benefit-cost analysis of community residential versus institutional services for adults with severe mental retardation and challenging behaviors. Am J Ment Retard 1995;99(5):533-41.

9. Davis JP, Judd FK, Herrman H. Depression in adults with intellectual disability. Part I:A review.Aust N Z J Psychiatry 1997;3I (2):232-42. 10. Brown RI, Brown I.The application of quality of life.J Intellect Disabil Res 2005;49:718-727.

II. de Bruyn, Maria. Gender and AIDS, Best practices/programs that work. http://data.unaids.org/Topics/Gender/bestpractices_en.pdf?preview=true. 12. Koornneef E. Measuring quality in services for children with an intellectual disability. Int J Health Care Qual Assur Inc Leadersh Health Serv 2006; | $9(4-5): 400-8$.

13. O'Hara J. Standards and quality measures for services for people with intellectual disabilities. Curr Opin Psychiatry 2006; I9(5):497-50I.

14. Martin G, Costello H, Leese M, Slade M, Bouras N, Higgins S, Holt G. An exploratory study of assertive community treatment for people with intellectual disability and psychiatric disorders: conceptual, clinical, and service issues.J Intellect Disabil Res 2005;49(Pt 7):516-24.

15. Xu J,Wang M, Xiang Y, Hu X. Quality of life for people with intellectual disabilities in China: a cross-culture perspectives study.J Intellect Disabil Res 2005;49(Pt 10):745-9.

16. Zhang D,Wehmeyr ML, Chen LJ. Parent and teacher engagement in fostering self-determination of students with disabilities:A comparison between the United States and the Republic of China. Remedial and Special Education 2005;26(I):55-64.

I7. Ruchlin HS, Morris JN. Pennsylvania's domiciliary care experiment: II. Cost-benefit implications.J Public Health 1983 Jun;73(6):654-60.

18. Mansell J,Ashman B, Macdonald S, Beadle-Brown J. Residential care in the community for adults with intellectual disability: needs, characteristics and services.J Intellect Disabil Res 2002 Nov;46(Pt 8):625-33.

19. Knobbe CA, Carey SP, Rhodes L, Horner RH. Benefit-cost analysis of community residential versus institutional services for adults with severe mental retardation and challenging behaviors Am J Ment Retard. 1995 Mar;99(5):533-4I.

20. Joyce T, Ditchfield H, Harris P. Challenging behaviour in community services.J Intellect Disabil Res 200I Apr;45(Pt 2):I30-8.

21. Holt G, Costello H, Bouras N, Diareme S, Hillery J, Moss S, RodriguezBlazquez C, Salvador L,Tsiantis J,Weber G, Dimitrakaki C. BIOMED-

MEROPE project: service provision for adults with intellectual disability: a European comparison.J Intellect Disabil Res 2000;44 ( Pt 6):685-96. 22. Heller T, Miller AB, Factor A. Environmental characteristics of nursing homes and community-based settings, and the well-being of adults with intellectual disability.J Intellect Disabil Res 1998;42 ( Pt 5):418-28.

23. Davis JP, Judd FK, Herrman H. Depression in adults with intellectual disability. Part I:A review.Aust N Z J Psychiatry 1997 Apr;3 I (2):232-42. 24. Dekker MC, Koot HM.DSM-IV disorders in children with borderline to moderate intellectual disability. II: child and family predictors. J Am Acad Child Adolesc Psychiatry 2003 Aug;42(8):923-31.

25. Wehmeyer ML, Bolding N. Enhanced self-determination of adults with intellectual disability as an outcome of moving to community-based work or living environments. Intellect Disabil Res 200I Oct;45(Pt 5):37I-83. 26. Llewellyn G, McConnell D, Bye R. Perception of service needs by parents with intellectual disability, their significant others and their service workers. Res Dev Disabil 1998 May-Jun; 19(3):245-60.

27. Mansell J, Elliott T, Beadle-Brown J,Ashman B, Macdonald S.

Engagement in meaningful activity and "active support" of people with intellectual disabilities in residential care. Res Dev Disabil 2002 SepOct;23(5):342-52.

28. Christian L, Snycerski SM, Singh NN, Poling A. Direct service staff and their perceptions of psychotropic medication in non-institutional settings 
for people with intellectual disability.J Intellect Disabil Res 1999 Apr;43 ( Pt 2):88-93.

29. Smiley E, Cooper SA, Miller SM, Robertson P, Simpson N. Specialist health services for people with intellectual disability in Scotland. Intellect Disabil Res 2002 Nov;46(Pt 8):585-93.

30. Hayden MF, Kim SH, DePaepe P. Health status, utilization patterns, and outcomes of persons with intellectual disabilities: review of the literature. Ment Retard 2005;43(3): 175-95.

3I. Gustavson KH, Umb-Carlsson O, Sonnander K.A follow-up study of mortality, health conditions and associated disabilities of people with intellectual disabilities in a Swedish county.J Intellect Disabil Res 2005;49(Pt I2):905-I4.

32. Ouellette-Kuntz H, Garcin N, Lewis ME, Minnes P, Martin C, Holden JJ.Addressing health disparities through promoting equity for individuals with intellectual disability. Can J Public Health 2005;96 Suppl 2:S8-22. 33. Bruininks RH, Chen TH, Lakin KC, McGrew KS. Components of personal competence and community integration for persons with mental retardation in small residential programs. Dev Disabil 1992;13(5):463-79. 34. Emerson E, Robertson J, Gregory N, Hatton C, Kessissoglou S, Hallam A, Jarbrink K, Knapp M, Netten A, Walsh PN. Quality and costs of supported living residences and group homes in the United Kingdom. Am J Ment Retard 200I Sep; I06(5):40I-I5.

35. Hatton C, Emerson E, Robertson J, Gregory N, Kessissoglou S, Walsh PN. The Resident Choice Scale: a measure to assess opportunities for self-determination in residential settings.J Intellect Disabil Res 2004;48(Pt 2):103-13.

36. Schwartz C, Rabinovitz S. Life satisfaction of people with intellectual disability living in community residences: perceptions of the residents, their parents and staff members.J Intellect Disabil Res 2003;47(Pt 2):75-84.

37. Wehmeyer ML, Bolding N. Enhanced self-determination of adults with intellectual disability as an outcome of moving to community-based work or living environments. J Intellect Disabil Res 200I;45(Pt 5):37I-83.

38. Ashaye O, Fernando L, Kohen D, Mathew G, Orrell M.A five-year follow-up study of older long-stay clients with intellectual disability using the Disability Assessment Schedule.J Intellect Disabil Res 1998 Apr;42 ( Pt 2): $|3|-6$.

39. Bruininks RH, Chen TH, Lakin KC, McGrew KS. Components of personal competence and community integration for persons with mental retardation in small residential programs. Dev Disabil 1992;13(5):463-79. 40. Emerson E, Robertson J, Gregory N, Hatton C, Kessissoglou S, Hallam A, Jarbrink K, Knapp M, Netten A, Walsh PN. Quality and costs of supported living residences and group homes in the United Kingdom. Am J Ment Retard 200I Sep; 106(5):40I-I5.

41. Duryea EJ. Doubling: enhancing the role play technique in schools. J Sch Health 1990 Mar;60(3): 106-7.

42. Widmer ED, Kempf-Constantin N, Robert-Tissot C, Lanzi F, Carminati GG. How central and connected am I in my family? Family-based social capital of individuals with intellectual disability. Res Dev Disabil 2007 Mar 23; [Epub ahead of print].

43. Herring S, Gray K, Taffe J, Tonge B, Sweeney D, Einfeld S. Behaviour and emotional problems in toddlers with pervasive developmental disorders and developmental delay: associations with parental mental health and family functioning.J Intellect Disabil Res 2006;50(Pt 12):874-82. 44. Blacher J, Neece CL, Paczkowski E. Families and intellectual disability. Curr Opin Psychiatry 2005;18(5):507-13.
45. Kelsey RM, Ornduff SR, McCann CM, Reiff S. Psychophysiological characteristics of narcissism during active and passive coping. Psychophysiology 200I Mar;38(2):292-303.

46. Emerson E, Kiernan C,Alborz A, Reeves D, Mason H, Swarbrick R, Mason L, Hatton C. The prevalence of challenging behaviors: a total population study. Res Dev Disabil 200I;22(I):77-93.

47. Joyce T, Ditchfield H, Harris P. Challenging behaviour in community services.J Intellect Disabil Res 200I;45(Pt 2): I30-8.

48. Crocker AG, Mercier C, Lachapelle Y, Brunet A, Morin D, Roy ME. Prevalence and types of aggressive behaviour among adults with intellectual disabilities. Intellect Disabil Res 2006;50(Pt 9):652-61. 49. Chung MC, Cumella S, Bickerton WL,Winchester C.A preliminary study on the prevalence of challenging behaviours. Psychol Rep 1996;79(3 Pt 2): $1427-30$.

50. Rahi JS, Manaras I, Tuomainen H, Hundt GL. Meeting the needs of parents around the time of diagnosis of disability among their children: evaluation of a novel program for information, support, and liaison by key workers. Pediatrics 2004; I 14(4):e477-82.

51. Clark CS. Transforming nursing education: a partnership social system for alignment with philosophies of care. Int J Nurs Educ Scholarsh 2005;2: 52. Dinwiddie FW. Humanistic behaviorism: a model for rapprochement in residential treatment milieus. Child Psychiatry Hum Dev 1975;5(4):254-9. 53. Pain H. Coping with a child with disabilities from the parents' perspective: the function of information. Child Care Health Dev 1999;25(4):299-312.

54. Taanila A, Jarvelin MR, Kokkonen J. Cohesion and parents' social relations in families with a child with disability or chronic illness. Int J Rehabil Res 1999;22(2): I01-9.

55. Taanila A, Jarvelin MR, Kokkonen J. Parental guidance and counseling by doctors and nursing staff: parents' views of initial information and advice for families with disabled children J Clin Nurs. 1998;7(6):505-I I. 56. Katz G, Rangel G, Rivero G. Enlaces. I Serie cursiva. McGraw-Hill. Interamericana Editores. México 1998: I-I 19.

57. Klein-Vogelbach S. Physiotherapy in the service of rehabilitation. Ther Umsch 197I Feb;28(2):69-73.

58. Kelsey RM, Ornduff SR, McCann CM, Reiff S. Psychophysiological characteristics of narcissism during active and passive coping. Psychophysiology 2001;38(2):292-303.

59. Duryea EJ. Doubling: enhancing the role-play technique in schools J Sch Health. 1990 Mar;60(3): 106-7.

60. Lin JD,Wu JL, Lee PN. Healthcare needs of people with intellectual disability in institutions in Taiwan: outpatient care utilization and implications.J Intellect Disabil Res 2003 Mar;47(Pt 3):169-80.

61. Deb S, Thomas M, Bright C. Mental disorder in adults with intellectual disability. I: Prevalence of functional psychiatric illness among a community-based population aged between 16 and 64 years. I Intellect Disabil Res 2001;45(Pt 6):495-505.

62. Krahn GL, Hammond L, Turner A.A cascade of disparities: health and health care access for people with intellectual disabilities. Ment Retard Dev Disabil Res Rev 2006;12(I):70-82.

63. Ruddick L. Health of people with intellectual disabilities: a review of factors influencing access to health care. $\mathrm{Br} J$ Health Psychol 2005; 10(Pt 4):559-70. 